\title{
INCLUSION COMPLEXES OF NICARDIPINE - HCI FOR ORAL ADMINISTRATION
}

\author{
F. S. Ghazy ${ }^{1}$, O. A. Sammour ${ }^{1}$, S. A. Ghareeb ${ }^{2}$, H. A. El-Ghamry ${ }^{1}$, M. M. Issa ${ }^{1}$ and G. F. Atia ${ }^{1}$ \\ ${ }^{1}$ Departments of Pharmaceutics and ${ }^{2}$ Pharmacology, Faculty of Pharmacy, Zagazig \\ University, Zagazig, Egypt
}

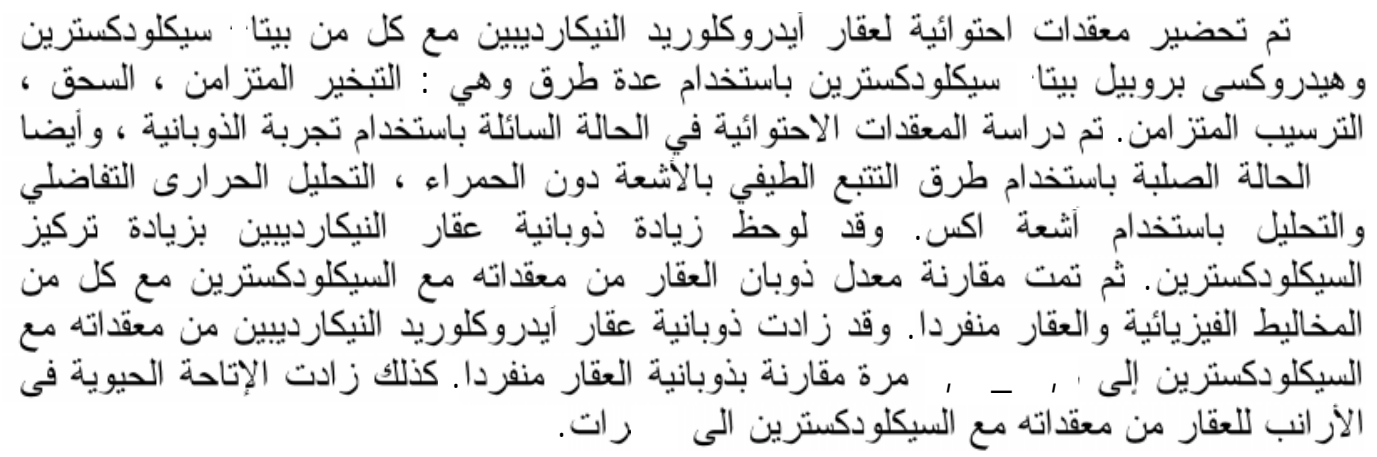

\begin{abstract}
Inclusion complexes of nicardipine $\mathrm{HCl}$ (NIC) with $\beta$-cyclodextrin $(\beta-C D)$ and hydroxypropyl- $\beta$-cyclodextrin $(H P-\beta-C D)$ were prepared using different methods: coevaporation, kneading and co-precipitation. Inclusion complexation in aqueous solution and in solid state was studied by the solubility method, Fourier transform-infrared spectroscopy $(F T I R)$, Differential scanning calorimetry $(D S C)$ and X-ray diffractometry (XRD). The solubility of (NIC) increased as a function of cyclodextrin concentration, showing Bs and AL type diagrams for $(\beta-C D)$ and $(H P-\beta-C D)$, respectively. The dissolution rate of $(N I C) /$ cyclodextrin complexes were investigated and compared with those of the physical mixtures and pure drug. The dissolution efficiency of (NIC) increased by complexation with cyclodextrins to 2.8-2.9 fold than (NIC) alone. Oral bioavailability in rabbits increased to $\sim 6$ fold by complexation with $(\beta-C D)$.
\end{abstract}

\section{INTRODUCTION}

(NIC) is a calcium entry blocker which is indicated for the prophylaxis of angina and mild to moderate hypertension. ${ }^{1}$ The main pharmaceutical drawbacks are substantially related to low solubility and fast photodecomposition. ${ }^{2}$ Moreover, the extensive presystemic (first-pass) metabolism of (NIC) is responsible for low bioavailability (approximately $30-45 \%$ after an oral dose of $40 \mathrm{mg})^{3}$

Cyclodextrins (CDs) are cyclic oligosaccharides of D-glucopyranose units $\alpha$ $(1,4)$ linked in a ring formation containing a relatively hydrophobic central cavity and a hydrophilic outer surface. They have the capacity to form inclusion complexes with many drugs by taking a whole drug molecule, or a part of it, into the cavity. ${ }^{4,5}$

The complexation with (CDs) is an established procedure to improve the biopharmaceutical properties of drugs with poor water solubility. The interaction of ketoprofen and ibuprofen with $(\beta-\mathrm{CD})$ in solution and in a solid state has been studied by Mura et al. ${ }^{6}$ Many other drugs have been tested for (CD) inclusion to enhance solubility such as glipizide, itraconazole, nimesulide and piroxicam. $^{7-10}$ The improved bioavailability of many drugs complexed with (CDs) has been documented in several articles. ${ }^{11-13}$

In the present study, the formation of NIC: $\beta-C D$ and NIC: HP- $\beta-C D$ complexes in solution was investigated by phase solubility. The complexes in the solid state were prepared 
by different techniques. Such complexes were characterized by FTIR, DSC and XRD. Moreover, the bioavailability of the drug from a selected formulation that exerted the highest rate and extent of dissolution was tested in comparison to drug alone.

\section{MATERIALS AND METHODS}

\section{Materials}

Nicardipine $\mathrm{HCl}$ and Procaine $\mathrm{HCl}$ (Kindly supplied by Misr Co., Egypt); $\beta$ cyclodextrin (MW = 1135), Hydroxypropyl- $\beta$ cyclodextrin $(\mathrm{MW}=1380)$ (Sigma, St. Louis, Mo, USA); Ethanol, Phosphate buffer, nhexane, Diethyl ether, Ammonium bromide and Triethanolamine (El-Nasr Co., Egypt); Methanol-HPLC grade (Honil Limited, London, U.K); Acetonitrile-HPLC grade (BDH Laboratory Supplies, England).

\section{Methods}

All experiments were carried out under conditions of protection from light since (NIC) is photosensitive in nature. ${ }^{2}$

\section{Phase solubility studies}

Phase solubility studies were performed according to the method reported by Higuchi and Connors. ${ }^{14}$ Excess amounts of (NIC) (120 $\mathrm{mg}$ ) were weighed into $25-\mathrm{ml}$ volumetric glass flasks, to which $20 \mathrm{ml}$ of distilled water containing various concentrations of (CDs) were added. With $\beta-C D$, the study was carried out up to its maximum solubility $(1.8 \% \mathrm{w} / \mathrm{v})$, meanwhile with HP- $\beta-C D$ it was carried out in the concentration range of $(0-15 \% \mathrm{w} / \mathrm{v})$. The securely capped flasks were placed in a water bath and shaken continuously at a constant temperature $\left(25 \pm 0.5^{\circ}\right)$ until equilibrium was reached (approximately 7 days). The samples were filtered through a double layered filter paper (Whatman 42). The filtered solutions were appropriately diluted and the amount of dissolved (NIC) was determined spectrophotometrically at $358 \mathrm{~nm}$. The studies were carried out in duplicate.

\section{Preparation of solid complexes}

Three methods were used for the preparation of the solid complexes (SCs). They were:

\section{I- Co-evaporation}

Amounts of (NIC) and (CDs) in the weight ratios 1:1, 1:2, 1:3, 1:5 and 1:10 (drug to $-\mathrm{CD} w / w)$ were dissolved at $40^{\circ}$ for $\beta-\mathrm{CD}$, and $20^{\circ}$ for HP- $\beta-C D$ in the lowest volume of $50 \%$ ethanol (which is necessary to obtain a solution) and maintained under stirring for 30 $\mathrm{min}$. The solvent was evaporated in a vacuum oven at $50^{\circ}$ until complete drying was obtained as checked by constant weight. ${ }^{15,16}$

\section{II- Kneading}

Amounts of (NIC) with either $\beta-\mathrm{CD}$ or HP- $\beta-C D$ in the optimal weight ratio that exhibited good dissolution properties (from co evaporates) were triturated with a small amount $(4 \mathrm{ml})$ of ethanol: water mixture (1:3). The slurry was kneaded for $60 \mathrm{~min}$ and then dried under vacuum at $40^{\circ}$ for $48 \mathrm{hrs} .^{17}$

\section{III- Co-precipitation}

Since the phase solubility diagram with $\beta$ $\mathrm{CD}$ was of the $\mathrm{B}_{\mathrm{s}}$ - type, solid complexes could be prepared by co precipitation, which is only possible for this type of phase solubility diagram. However, the application of this method in the pharmaceutical field is rather difficult because of the significantly low yield of the complex.

The solid complex was prepared by mixing appropriate amounts of (NIC) and $\beta-\mathrm{CD}$ in water. The appropriate mixture was determined by examining the descending curvature of the $\mathrm{B}_{\mathrm{s}}$-type phase solubility diagram. For example, $0.6 \mathrm{~g}$ of (NIC) and $1.5 \mathrm{~g}$ of $\beta$-CD were added to $100 \mathrm{ml}$ of water and the mixture was stirred at $25^{\circ}$ for 7 days. The complex, which precipitated as a microcrystalline powder, was removed by filtration and dried under vacuum at $40^{\circ}$ for 24 hrs. $^{18}$

\section{Preparation of physical mixtures (PMs)}

Fine powdered (PMs) of (NIC) with $\beta$ - or HP- $\beta$-CD with guest -host weight ratios of $1: 1$, $1: 2,1: 3,1: 5$ and $1: 10 \mathrm{w} / \mathrm{w}$ were prepared by blending in a mortar for $5 \mathrm{~min}$.

Powder of (NIC), (PMs) and (SCs) were sieved to obtain particles passing through 355 um and retained on 150 um sieve. 


\section{Dissolution studies}

Review of literature did not reveal any compendial method for the dissolution testing of (NIC). However, Said et al., ${ }^{19}$ used the rotating basket method to determine the intrinsic dissolution rates of (NIC) in $500 \mathrm{ml}$ of purified water maintained at $37^{\circ}$ and at a rotation of $100 \mathrm{rpm}$.

Dissolution studies were performed using the rotating paddle method. Samples of (NIC), (PMs) and (SCs) equivalent to $20 \mathrm{mg}$ of (NIC) were added to the dissolution medium $(900 \mathrm{ml}$ of dist. $\mathrm{H}_{2} \mathrm{O}$ at a temperature of $37^{\circ}$ ). The latter was stirred with a rotating paddle at $100 \mathrm{rpm} .5$ $\mathrm{ml}$ samples were withdrawn at appropriate time intervals $(2,6,12,20,30,40,50$ and $60 \mathrm{~min})$, filtered (Whatman 42), appropriately diluted and analyzed for (NIC) spectrophotometrically at $358 \mathrm{~nm}$. The same volume of fresh medium was replaced and correction for cumulative dilution was calculated.

The amount of (NIC) dissolved at different time intervals was calculated using a standard calibration curve developed in the same medium. Each experiment was carried out in triplicates.

\section{Fourier transform infrared spectroscopy}

Fourier transform IR spectra were obtained on a Perkin-Elmer 1600 FTIR spectrophotometer using $\mathrm{KBr}$ disk method. The scanning range was $400-4000 \mathrm{~cm}^{-1}$ and the resolution was $1 \mathrm{~cm}^{-1}$.

\section{Differential scanning calorimetry}

The DSC thermograms were recorded on a Shimadzu-DSC 50. Samples $(1.3 \mathrm{mg})$ were heated in hermetically sealed aluminum pans over the temperature range of $30-300^{\circ}$ at a constant rate of $10^{\circ} /$ min under a nitrogen purge (30 $\mathrm{ml} / \mathrm{min})$.

\section{X-ray diffraction}

$\mathrm{X}$-ray diffraction patterns were obtained using a Siemens Kristallofex D-5000 powder diffractometer with $\mathrm{CuK} \alpha$ radiation. Diffractograms were run at a scanning speed of $8^{\circ} /$ min over the $2 \theta$ range of $0-80^{\circ}$.

\section{Bioavailability study a- Study design}

Six rabbits (weighing 3-3.5 kg) were randomly divided into 2 groups of three rabbits each (parallel design). The study was designed as a single oral dose. An equivalent amount to $4.2 \mathrm{mg}$ drug / $\mathrm{kg}$ body weight of rabbits, was calculated for each product. Each group received a single dose of one of the following (A: "NIC" alone and B: NIC- $\beta-C D, 1: 10 \mathrm{w} / \mathrm{w}$ ). Each of the (NIC) systems was suspended in 5 $\mathrm{ml}$ water with $5 \%$ acacia and given orally to the rabbit through a stomach tube.

Blood samples $(3 \mathrm{ml})$ were drawn through the sinus orbital at $0,5,10,20,30,45,60,75$, $90,120,180,240,360$ and 480 min after each product administration. The blood samples were placed in heparinized tubes, centrifuged immediately for $10 \mathrm{~min}$ at $3000 \mathrm{rpm}$ to obtain plasma samples, and were stored at $-20^{\circ}$ for subsequent assay.

\section{b- Sample preparation}

An internal standard (Procaine $\mathrm{HCl}$ ) solution $(1 \mathrm{ug} / \mathrm{ml})$ was prepared in a mixture of $0.1 \mathrm{M}$ phosphate buffer $\mathrm{pH} 7.4$ and absolute ethanol (20: 1).

One $\mathrm{ml}$ of internal standard solution and 6 $\mathrm{ml}$ of diethylether - $\mathrm{n}$-hexane (1:1) were added to $1 \mathrm{ml}$ of plasma in a $10-\mathrm{ml}$ centrifuge tube equipped with a stopper. The tube was shaken for $15 \mathrm{~min}$ on a mechanical shaker and centrifuged for $10 \mathrm{~min}$ at $3000 \mathrm{rpm}$. The organic layer was transferred to another $10-\mathrm{ml}$ tube and evaporated at $50^{\circ}$ to dryness in an oven. The residue was dissolved in $0.6 \mathrm{ml}$ of the HPLC eluent, then filtered through a Millipore filter of $0.4 \mathrm{um}$. A volume of $80 \mathrm{ul}$ of filtered solution was automatically injected onto the column. ${ }^{20}$

The concentration of (NIC) in samples was determined from calibration curve of the peak area ratio versus plasma nicardipine $\mathrm{HCl}$ concentration.

\section{c- HPLC conditions}

HPLC (Kontron Instruments, Switzerland) system consisted of HPLC pump 420 (pump A and pump B), mixing pump 494, multiport computer RS-232, HPLC autosampler 460, and oven controller 480. Temperature column oven 480, fixed with reverse phase C18 column (inert sil ODS-2, $4.6 \times 250 \mathrm{~mm}$, 5 um particle size and pre column). HPLC detector 430 with range of 0.2 , resp. time 0.05 , remote, monitor Mitsubishi and data system computer 450 . 
The mobile phase of (NIC) analysis consisted of methanol - $0.04 \mathrm{M}$ ammonium bromide in water - acetonitrile (40:36:24) and $0.6 \mathrm{ml}$ of triethanolamine to give a $\mathrm{pH}$ of 7.8 (21). The mobile phase mixture was degassed by ultrasonification immediately before use. The eluent was passed through the column at a flow-rate of $1 \mathrm{ml} / \mathrm{min}$ which generated a pressure of approximately 114 bar. The eluent was monitored at $254 \mathrm{~nm}$. Although monitoring at $238 \mathrm{~nm}$ gave the highest peak for (NIC), endogenous substances may interfere. At 254 $\mathrm{nm}$, however, there is no interference and no peaks appeared at the retention time of (NIC). The retention time for procaine $\mathrm{HCl}$ was 5.7 min and for (NIC) it was $12.88 \mathrm{~min}$.

\section{d- Data analysis}

The maximum plasma concentration $\left(\mathrm{C}_{\max }\right)$ and time to reach the $\mathrm{C}_{\max }$ concentration $\left(\mathrm{T}_{\max }\right)$ were obtained directly from the plasma concentration-time curve. ${ }^{22}$ The area under the curve (AUC) of plasma concentration vs. time $(0-8 \mathrm{hr})$ was calculated by the trapezoidal method. ${ }^{22}$ Mean residence time (MRT) was calculated from the following equation: ${ }^{23}$

$$
\mathrm{MRT}=\mathrm{AUMC}_{0-8 \mathrm{~h}} / \mathrm{AUC}_{0-8 \mathrm{~h}}
$$

Where, AUMC is the area under the (time $\mathrm{x}$ nicardipine $\mathrm{HCl}$ concentration) versus time curve. Relative bioavailability was calculated from the comparison of the $\mathrm{AUC}_{0-8 \mathrm{~h}}$ of the solid complex with that for the drug suspension. $^{21}$

\section{RESULTS AND DISCUSSION}

\section{Phase solubility studies}

Figure 1 shows the equilibrium phase solubility diagrams obtained for (NIC) with the two (CDs) used. The drug solubility increased linearly, in accord with the amount of HP- $\beta-C D$ added; the diagram is of $\mathrm{A}_{\mathrm{L}^{-}}$type. Recently, Rajewski and Stella, ${ }^{24}$ described that when there is a linear increase in drug solubility with increasing (CD) concentration, a (CD) complex of a drug results from 1:1 mol / mol interaction. However the solubility curve in the case of $\beta$ $\mathrm{CD}$, was a Bs-type with the precipitation of microcrystalline NIC- $\beta$-CD complex at high $\beta$ $\mathrm{CD}$ concentrations. The stoichiometry of NIC$\beta$-CD complex was (1:5, molar ratio). It was estimated from the data in the plateau region of solubility diagram, following the calculation: ${ }^{25}$

$$
\text { Molar ratio }=\frac{\text { Total guest in the system }- \text { dissolved guest at beginning of plateau }}{\beta-\text { CD concentration differences in plateau }}
$$
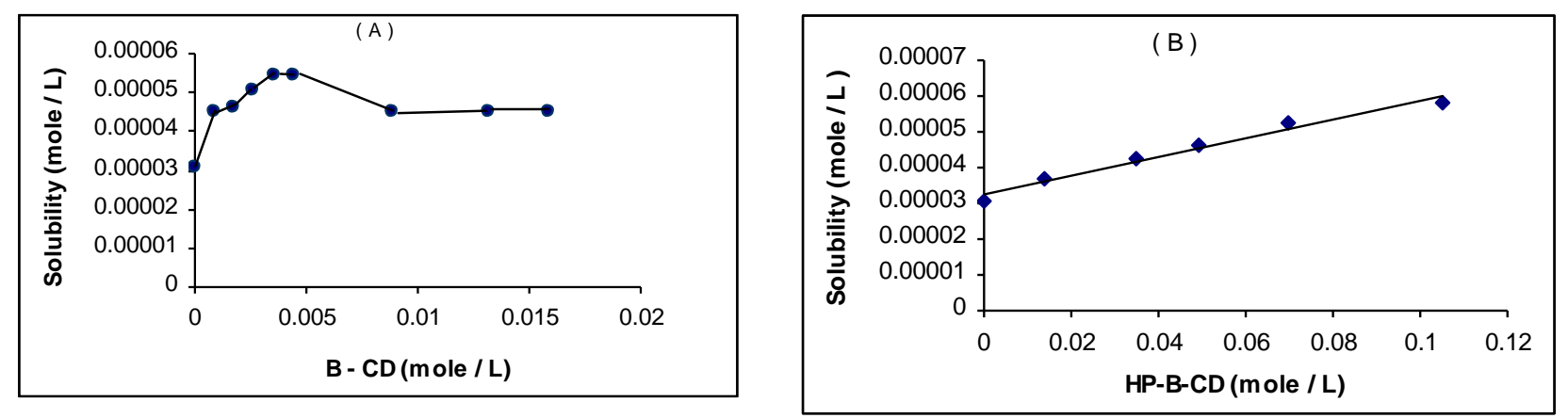

Fig. 1: Phase Solubility Diagram of ( NIC ) in Presence of (A) $\beta-C D$ and (B) HP- $\beta-C D$ in Water at $25^{\circ}$. 
The extent of complexation in aqueous media is characterized by the stability constant (K). It is calculated according to Higuchi and Connors, ${ }^{14}$ from the following equation:

$$
\mathrm{K}=\text { slope / S0 ( } 1 \text { - slope })
$$

Where S0 is the drug solubility in absence of (CDs).

The apparent stability constant was found to be $8.19 \mathrm{M}^{1}$ for HP- $\beta$-CD, suggesting that the inclusion compounds formed were not sufficiently stable. While, the $\mathrm{K}$ value for $\beta$-CD was $196.8 \mathrm{M}^{1}$, which is nearly included in the range of 200 and $5000 \mathrm{M}^{1}$, considered by various authors as the most suitable, given that, in this range, the formation of an inclusion complex may contribute to the improvement of bioavailability of poorly soluble drugs. ${ }^{26}$ The reduced complexation activity of HP- $\beta-C D$ was consistent with the results for many drugs and may be due to the steric hindrance of the substituent groups because (NIC) is a rather bulky molecule. ${ }^{6,27}$

Table 1 summarizes the phase solubility data of the complexes obtained.

Table 1: Summary of findings from the phase solubility studies of (NIC) with different cyclodextrins.

\begin{tabular}{|c|c|c|}
\hline Item & B-CD & $\mathrm{HP}-\beta-\mathrm{CD}$ \\
\hline Type of diagram & $\mathrm{B}_{\mathrm{s}}$ & $\mathrm{A}_{\mathrm{L}}$ \\
\hline $\begin{array}{c}\text { Molar ratio } \\
\text { ( drug - to - CD ) }\end{array}$ & $1: 5$ & $1: 1$ \\
\hline Intercept & $3.48 \times 10^{-5}$ & $3.269 \times 10^{-5}$ \\
\hline Slope & $5.99 \times 10^{-3}$ & $2.508 \times 10^{-4}$ \\
\hline $\begin{array}{l}\text { Correlation } \\
\text { coeffecient }\end{array}$ & 0.9272 & 0.9879 \\
\hline $\begin{array}{l}\text { Stability constant } \\
(\mathrm{K})\left(\mathrm{M}^{1}\right)\end{array}$ & 196.8 & 8.19 \\
\hline Solubility factor ${ }^{a}$ & 1.8 & 1.9 \\
\hline
\end{tabular}

Solubility factor ${ }^{\mathrm{a}}=$ Total solubility/intrinsic solubility. $\mathrm{A}_{\mathrm{L}}, \mathrm{B}_{\mathrm{s}}=$ Types of phase solubility diagrams.

Fernandes et al., ${ }^{28}$ studied the inclusion complexation between (NIC) and $\beta$-CD or HP$\beta$-CD in aqueous environment. They classified the phase solubility profiles with both (CDs) as $\mathrm{A}_{\mathrm{L}}$-type and stated that, more stable NIC-CDs complexes were formed in alkaline medium in which the drug is in its non-ionized form.

\section{Dissolution studies}

The mean dissolution curves of (NIC) from various binary systems with (CDs) are presented in Figures 2-5. The results in terms of initial dissolution rate over the first $20 \mathrm{~min}$ (IDR), time to dissolve $50 \%$ drug $\left(\mathrm{t}_{50 \%}\right)$, percent of active ingredient dissolved after 60 min (DP60) and dissolution efficiency after 60 min (DE\%) are collected in Tables 2, 3. It is clear that all the systems with (CDs) exhibited better dissolution properties than drug alone. The increased dissolution rate of (PMs) was attributable both to improvement in drug wettability and to formation of readily soluble complexes in the dissolution medium. ${ }^{29}$ As for the other systems, in case of combinations with $\beta$-CD (Table 2), co-evaporation was found to be the most effective technique in achieving the enhancement of drug dissolution rate $\left(\mathrm{t}_{50 \%} \sim 28\right.$ $\min$ ), followed in order by kneading and co precipitation. Also, for preparations with HP- $\beta$ $\mathrm{CD}$, co-evaporation method showed greater improvement $\left(\mathrm{t}_{50 \%}=35.6 \mathrm{~min}\right)$ compared to kneading method $\left(\mathrm{t}_{50 \%}=89.4 \mathrm{~min}\right)$. The greater performance of complexes prepared by co evaporation rather than those prepared by kneading or co precipitation could be ascribed to complete complex formation. This result was consistent with that reported by Veiga et al. ${ }^{17}$ and Tenjarla et al. ${ }^{30}$

The observed increase in dissolution rate from (CD) complexes may be due to the increase in solubility as mentioned before in solubility studies. Other workers had suggested that dissolution rates from (CD) complexes are also dependent on other factors: these include diffusion and dissociation in the dissolution medium, ${ }^{31}$ decrease in crystallinity and enhanced wettability of the drug by the inclusion complexation. ${ }^{32}$

It was not guaranteed that the powder obtained was a true homogenous inclusion complex. The isolated solid product may only be a finely dispersed mixture of host and guest. In many cases the product is a mixture of complex, uncomplexed guest, and empty i.e. hydrated (CD). The question may be clarified by applying the suitable methods i.e. FTIR spectroscopy, DSC and X-ray diffractometry. 


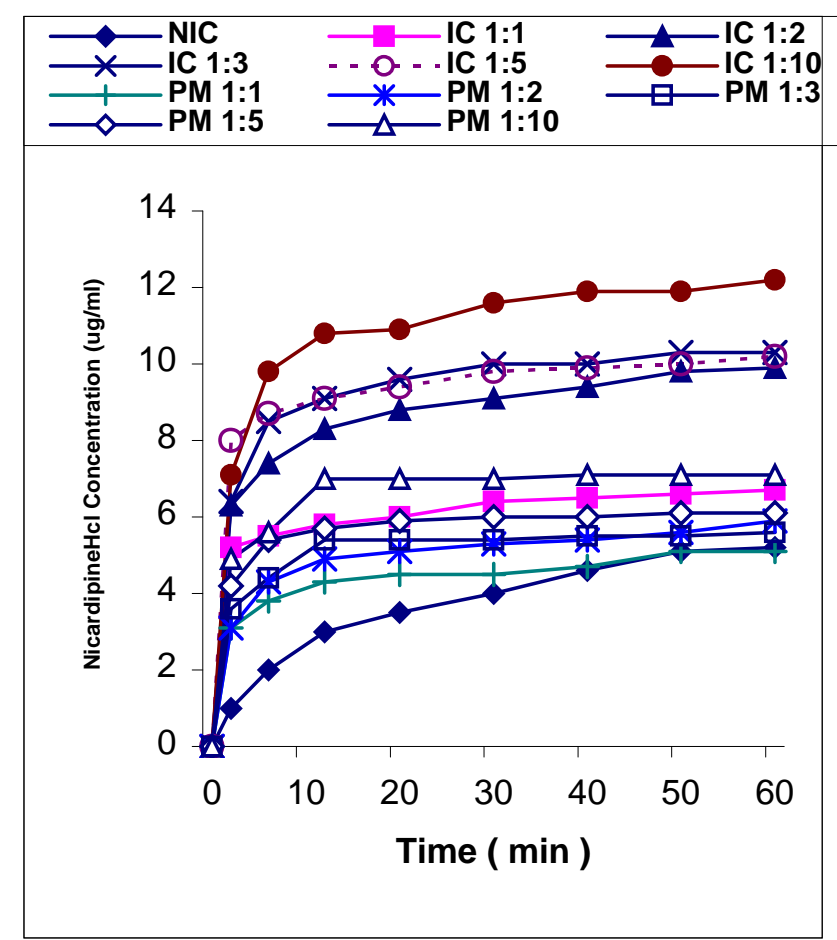

Fig. 2: Dissolution profiles of (NIC) from NIC- $\beta-C D$ systems in dist.water at $37^{\circ}$.

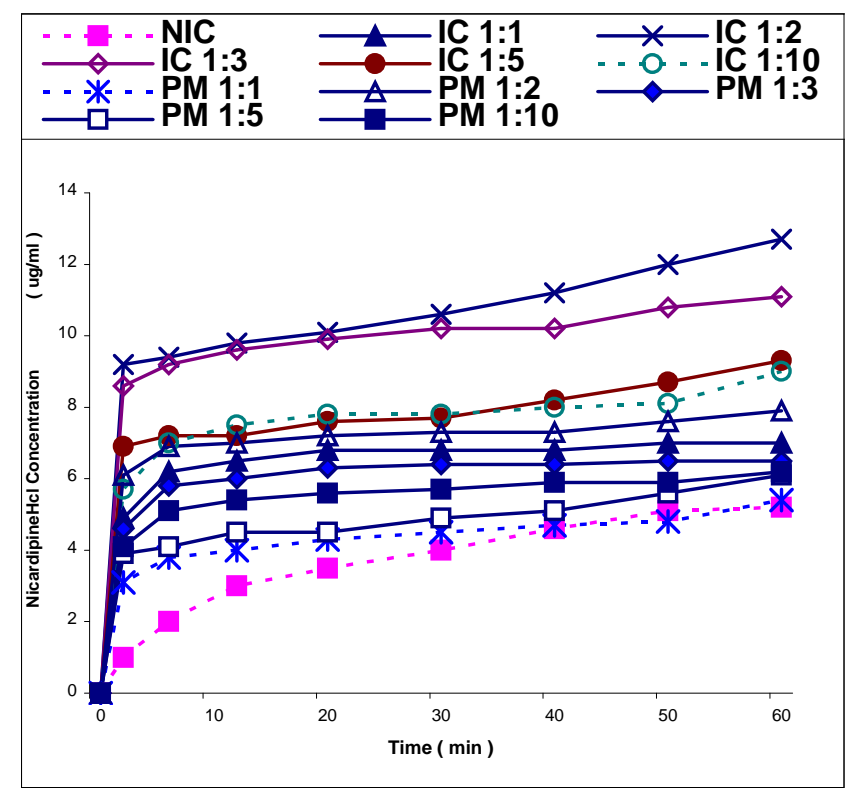

Fig. 4: Dissolution profiles of (NIC) from NIC-HP- $\beta-C D$ systems in dist. water at $37^{\circ}$.

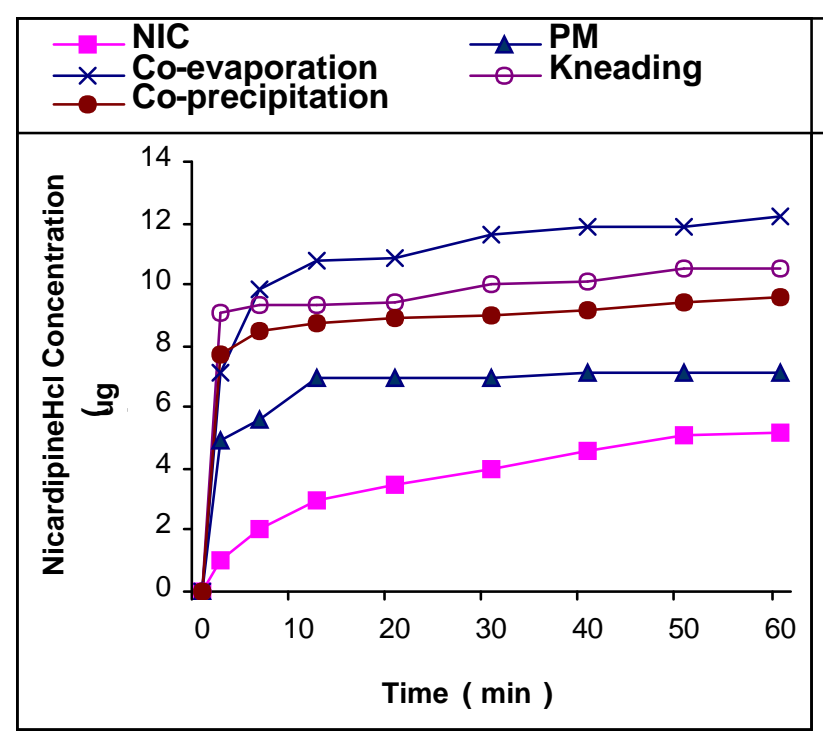

Fig. 3: Effect of method of preparation on the dissolution of (NIC) from $(1: 10)$ NIC- $\beta$-CD complex.

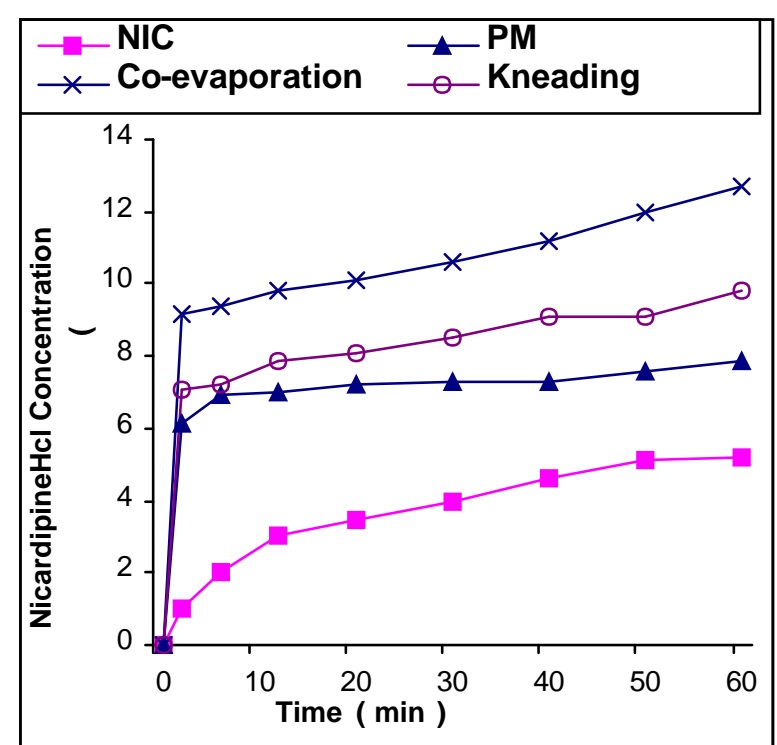

Fig. 5: Effect of method of preparation on the dissolution of (NIC) from (1:2) NIC-HP- $\beta$-CD complex. 
Table 2: Dissolution parameters of ( NIC ) for different NIC- $\beta$-CD systems.

\begin{tabular}{|lc|c|c|c|c||}
\hline \multicolumn{2}{|c|}{$\begin{array}{c}\text { Composition } \\
(\mathrm{w} / \mathrm{w})\end{array}$} & $\begin{array}{c}\text { IDR } \\
(\% \text { dissolved } / \mathrm{min})\end{array}$ & $\mathrm{T}_{50 \%}(\min )$ & $\mathrm{DP}_{60}(\%)$ & $\mathrm{DE} \%$ \\
\hline NIC & $0.8 \pm 0.02$ & $246 \pm 18.1$ & $23.4 \pm 0.48$ & $17.1 \pm 0.24$ \\
\hline NIC- to $-\beta$-CD & & & & \\
\hline PM & $1: 1$ & $1.01 \pm 0.03$ & $>246$ & $23.00 \pm 0.43$ & $20.1 \pm 0.38$ \\
IC & $1: 1$ & $1.35 \pm 0.03$ & $196.2 \pm 12.8$ & $30.2 \pm 1.44$ & $27.5 \pm 0.57$ \\
\hline PM & $1: 2$ & $1.15 \pm 0.07$ & $>246$ & $26.6 \pm 0.96$ & $22.8 \pm 1.57$ \\
IC & $1: 2$ & $1.98 \pm 0.11$ & $88.5 \pm 11.39$ & $44.6 \pm 0.95$ & $39.4 \pm 1.73$ \\
\hline PM & $1: 3$ & $1.2 \pm 0.06$ & $>246$ & $25.2 \pm 0.9$ & $23.3 \pm 0.61$ \\
IC & $1: 3$ & $2.16 \pm 0.14$ & $68.6 \pm 6.75$ & $46.4 \pm 0.29$ & $42.5 \pm 1.6$ \\
\hline PM & $1: 5$ & $1.3 \pm 0.03$ & $>246$ & $27.5 \pm 1.17$ & $25.8 \pm 0.26$ \\
IC & $1: 5$ & $2.1 \pm 0.03$ & $88.2 \pm 9.97$ & $45.9 \pm 0.95$ & $42.3 \pm 0.53$ \\
\hline PM & $1: 10$ & $1.6 \pm 0.06$ & $>246$ & $32.00 \pm 1.17$ & $30.2 \pm 0.45$ \\
IC & $1: 10$ & $2.5 \pm 0.11$ & $27.9 \pm 7.32$ & $54.9 \pm 0.9$ & $49.4 \pm 1.89$ \\
IC & $1: 10$ & $2.1 \pm 0.06$ & $81.3 \pm 7.06$ & $47.3 \pm 0.93$ & $43.6 \pm 0.64$ \\
IC $^{\mathrm{b}}$ & $1: 10$ & $2.00 \pm 0.02$ & $136.7 \pm 14.6$ & $43.2 \pm 0.9$ & $39.8 \pm 0.2$ \\
\hline \hline
\end{tabular}

$\mathrm{IC}^{\mathrm{a}}=\mathrm{IC}$ prepared by solvent - evaporation. $\quad \mathrm{IC}^{\mathrm{b}}=\mathrm{IC}$ prepared by kneading.

$\mathrm{IC}^{\mathrm{c}}=\mathrm{IC}$ prepared by co-precipitation.

Each result is the average of three determinations $( \pm \mathrm{SD})$.

Table 3: Dissolution parameters of (NIC) for different NIC-HP- $\beta-C D$ systems.

\begin{tabular}{|lc|c|c|c|c||}
\hline \multicolumn{2}{|c|}{$\begin{array}{c}\text { Composition } \\
(\mathrm{w} / \mathrm{w})\end{array}$} & $\begin{array}{c}\text { IDR } \\
(\% \text { dissolved/ } \min )\end{array}$ & $\mathrm{t}_{50 \%}(\mathrm{~min})$ & $\mathrm{DP}_{60}(\%)$ & $\mathrm{DE} \%$ \\
\hline NIC & $0.8 \pm 0.02$ & $246 \pm 18.1$ & $23.4 \pm 0.48$ & $17.1 \pm 0.24$ \\
\hline NIC- to -HP- $\beta$-CD & & & & \\
\hline PM & $1: 1$ & $1.00 \pm 0.02$ & $221.3 \pm 5.00$ & $24.3 \pm 0.45$ & $19.6 \pm 0.52$ \\
$\mathrm{IC}$ & $1: 1$ & $1.5 \pm 0.05$ & $140.7 \pm 2.1$ & $31.5 \pm 1.33$ & $29.5 \pm 0.06$ \\
\hline PM & $1: 2$ & $1.6 \pm 0.047$ & $153.9 \pm 9.95$ & $35.6 \pm 0.45$ & $32.1 \pm 0.42$ \\
IC & $1: 2$ & $2.3 \pm 0.02$ & $35.6 \pm 1.84$ & $57.1 \pm 0.29$ & $47.7 \pm 0.49$ \\
IC & $1: 2$ & $1.8 \pm 0.05$ & $89.4 \pm 2.5$ & $44.3 \pm 0.4$ & $37.6 \pm 0.57$ \\
\hline PM & $1: 3$ & $1.4 \pm 0.05$ & $172.7 \pm 2.26$ & $29.3 \pm 1.65$ & $27.5 \pm 0.35$ \\
IC & $1: 3$ & $2.2 \pm 0.02$ & $58.4 \pm 3.46$ & $50.00 \pm 0.9$ & $44.6 \pm 0.25$ \\
\hline PM & $1: 5$ & $1.00 \pm 0.03$ & $173.6 \pm 4.15$ & $27.5 \pm 0.9$ & $21.8 \pm 0.52$ \\
IC & $1: 5$ & $1.7 \pm 0.051$ & $112.1 \pm 4.03$ & $41.9 \pm 0.45$ & $35.1 \pm 0.62$ \\
\hline PM & $1: 10$ & $1.3 \pm 0.05$ & $175.9 \pm 5.00$ & $27.9 \pm 0.45$ & $24.9 \pm 0.46$ \\
IC & $1: 10$ & $1.8 \pm 0.051$ & $104.5 \pm 4.73$ & $40.5 \pm 0.81$ & $34.4 \pm 0.53$ \\
\hline
\end{tabular}

$\mathrm{IC}^{\mathrm{a}}=$ IC prepared by solvent - evaporation. $\quad \mathrm{IC}^{\mathrm{b}}=$ IC prepared by kneading.

Each result is the average of three determinations $( \pm \mathrm{SD})$. 


\section{Fourier - transform infrared spectroscopy}

Infrared spectra of (NIC), as well as those of its different systems with (CDs), are represented in Figures 6, 7. As evidenced from the spectra, the N-H stretching band of (NIC) (at $3394 \mathrm{~cm}^{-1}$ ) disappeared completely in case of (PMs) and (SCs) with the predominance of the $\mathrm{O}-\mathrm{H}$ band of the (CDs) (at $3397 \mathrm{~cm}^{-1}$ ) which was shifted to $3381-3383 \mathrm{~cm}^{-1}$ in case of $\beta$-CD systems (Figure 6). Moreover, in case of NIC-CDs complexes, there was a marked reduction in the intensity of some bands $(\mathrm{C}=\mathrm{O}$, $\mathrm{C}=\mathrm{C}$ ) and some other bands were practically undetectable (C-N, C-O). All these modifications may probably occur as a consequence of inclusion complex formation. . $^{3,34}$

\section{Differential scanning calorimetry}

The DSC thermograms of the (PMs) of "NIC" and (CDs) as well as those of the solid binary complexes are shown in Figures 8, 9. The thermal curve of (NIC) $\left(\right.$ Tpeak $=164.08^{\circ}$, $\Delta \mathrm{H}_{\mathrm{f}}=81.29 \mathrm{~J} / \mathrm{g}$ ) indicated its crystalline anhydrous state. Liberation of crystal water from $\beta-C D$ was observed as an endothermal

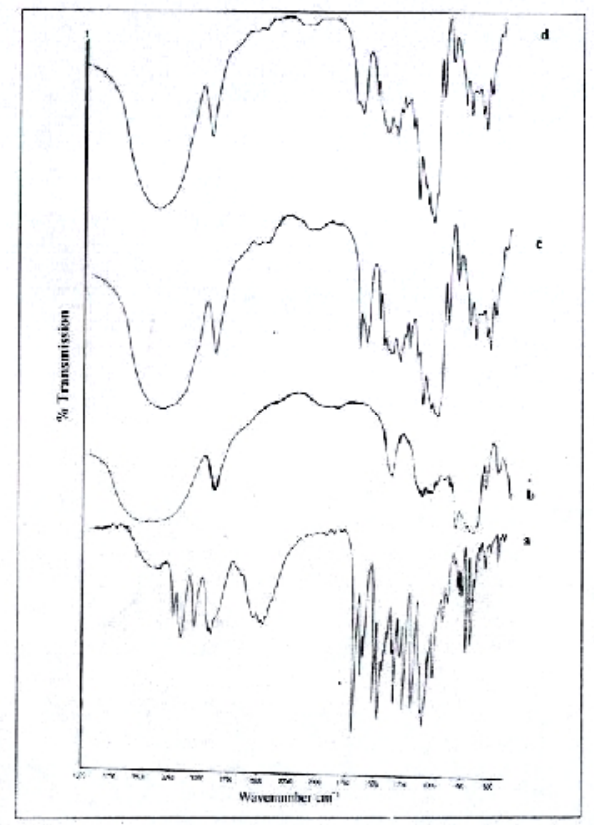

Fig. 6: FTIR spectra of NIC- $\beta$-CD systems: a) NIC; b) pure $\beta-C D$; $)$ PM $(1: 10)$ and d) IC (1:10). effect peaked at $88.41^{\circ}$, whereas a broader endotherm effect, associated with water loss (at $60.53^{\circ}$ ) was recorded for amorphous HP- $\beta$-CD.

In case of $\beta-C D$ systems, the (PM) exhibited two peaks at $72.05^{\circ}$ and at $102.15^{\circ}$ due to dehydration of $\beta-\mathrm{CD}$. As can be seen, there is splitting in the $\beta$-CD endothermic peak which may be due to weak interaction during the development of the thermogram. ${ }^{35}$ While, the solid complex displayed an endothermal band at $85.14^{\circ}$ due to the dehydration of $\beta-C D$ and a very broad small endothermal peak at $214.65^{\circ}$ which may be due to the shift of melting point of (NIC) to a higher temperature as a result of inclusion complex formation. ${ }^{17}$

The characteristic thermal profile of the drug was present in its)PM (with HP- $\beta-C D$. The solid complex of the drug showed a complete disappearance of the (NIC) thermal profile which indicates the formation of an amorphous solid dispersion, molecular encapsulation of the drug inside the (CD) cavity, or both. ${ }^{36,37}$

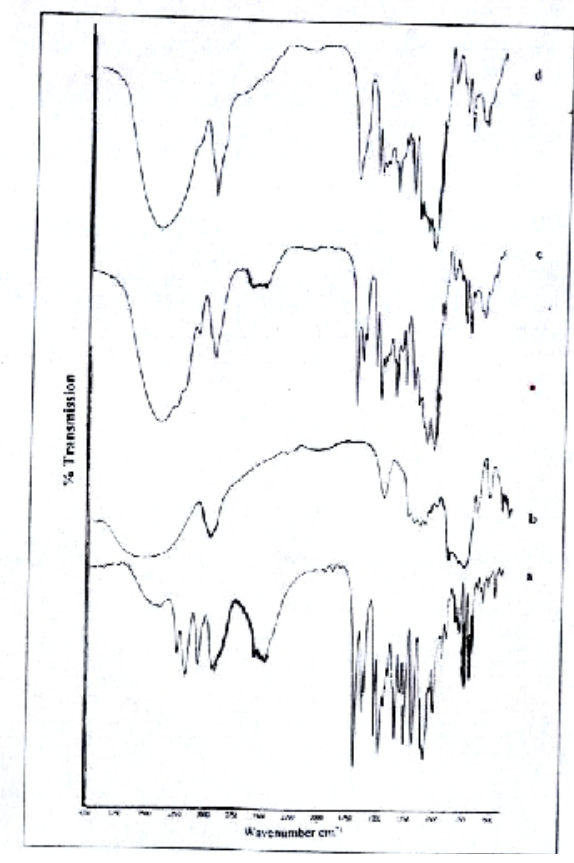

Fig. 7: FTIR spectra of NIC-HP- $\beta$-CD systems: a) NIC; b) pure HP- $\beta-C D$; c) PM $(1: 2)$ and d) IC (1:2). 


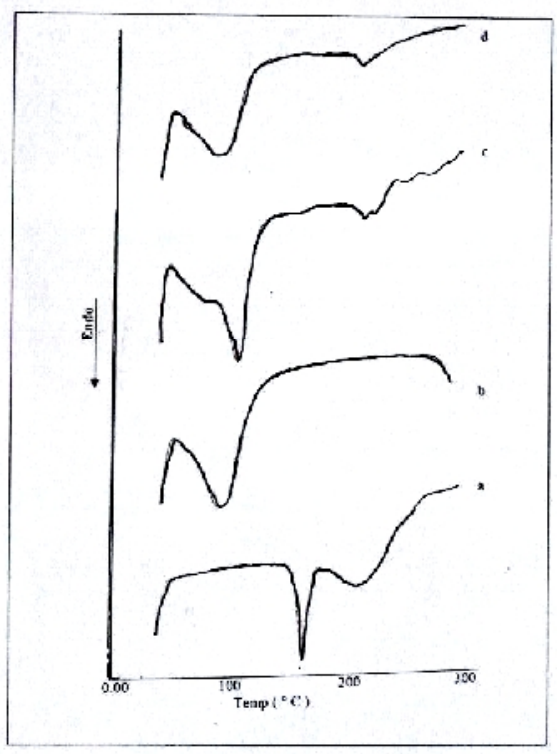

Fig. 8: DSC thermograms of NIC- $\beta$-CD systems: a) NIC; b) pure $\beta-C D$; c) PM $(1: 10)$ and d) IC $(1: 10)$.

\section{X-ray diffraction}

X-ray powder diffraction patterns (Figures $10,11)$ confirmed the results of DSC analysis. Patterns of the NIC- $\beta$-CD (PM) demonstrated nearly a simple superposition of each component, while that of the co evaporated sample was clearly different from each constituent and constituted a new solid phase. The $\beta$-CD complex gave somewhat diffuse diffraction patterns, suggesting that they are less crystalline than the (PM). ${ }^{38}$ In the (PM) with HP- $\beta-C D$, the presence of free crystalline (NIC) was revealed by few and broad peaks of low intensity which emerged on the diffuse background due to the amorphous carrier, indicating a clear loss of crystallinity of the drug. Only one diffraction peak attributable to (NIC) was still detectable also in the complex but in this case the finer dispersion in the carrier phase, due to the co evaporation method, makes the drug in a high energy state prone to be brought to an almost totally amorphous state by the thermal energy supplied during a DSC scan. ${ }^{36}$

\section{Bioavailability assessment}

The NIC- $\beta$-CD $(1: 10$, w/w) co-precipitate was expected to have good bioavailability after oral administration because its dissolution and release rates were significantly superior to those of drug alone. Thus, (NIC) and its $\beta$-CD co-precipitate were administered orally to

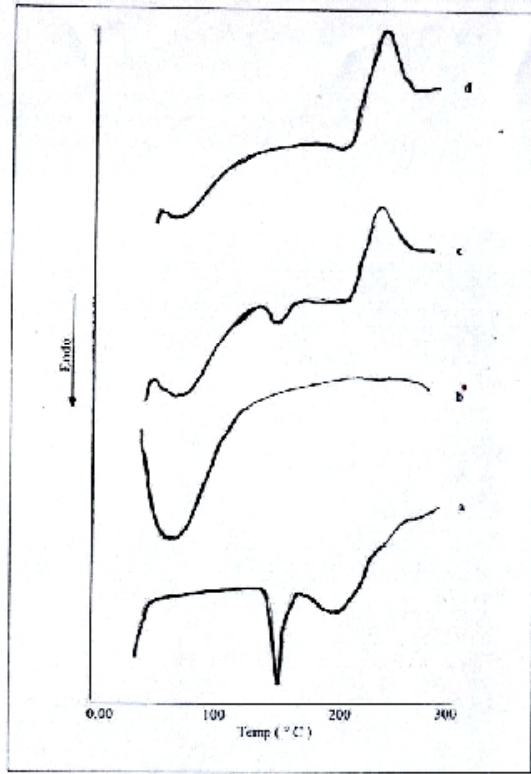

Fig. 9: DSC thermograms of NIC-HP- $\beta-C D$ systems: a) NIC; b) pure HP- $\beta-C D$; c) PM (1:2) and d) IC (1:2).

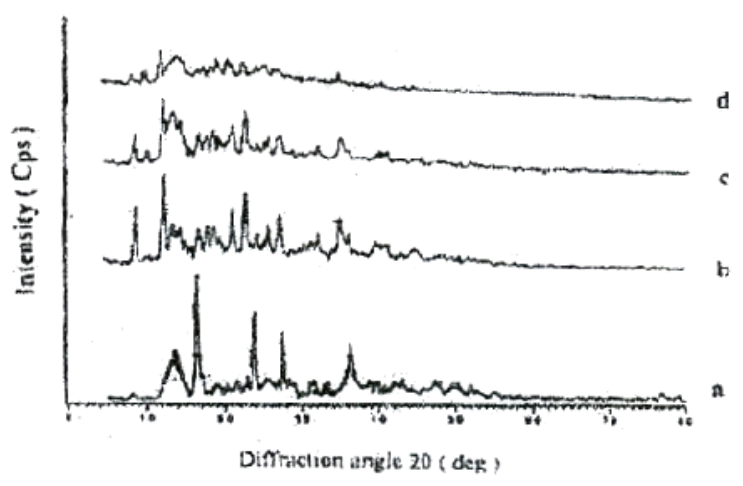

Fig. 10: X-ray diffraction patterns of NIC- $\beta-C D$ systems: a) NIC; b) pure $\beta-\mathrm{CD}$; c) $\mathrm{PM}$ $(1: 10)$ and d) IC (1:10).

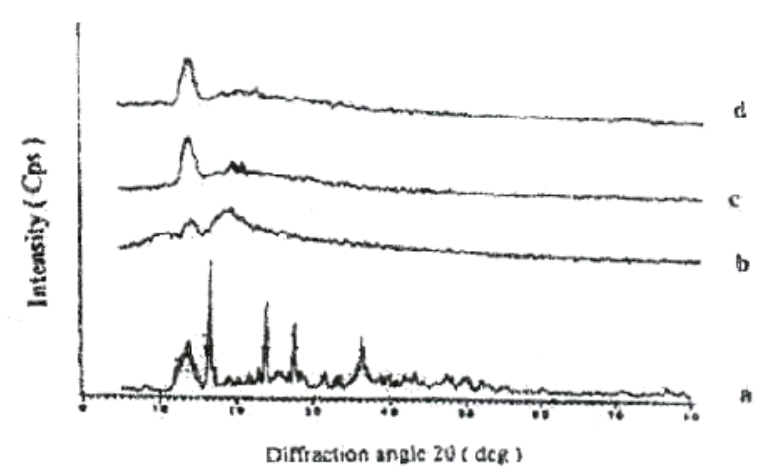

Fig. 11: X-ray diffraction patterns of NIC-HP- $\beta-C D$ systems: a) NIC; b) pure HP- $\beta-C D$; c) PM (1:2) and d) IC (1:2). 
rabbits to evaluate their absorption characteristics. The graphical illustration of the mean (NIC) concentration in plasma as a function of time appears in Figure 12. It is obvious that there is a clear difference between the biological performance of the drug and the prepared co-precipitate which reflected itself by an apparent higher (NIC) levels. The mean values of pharmacokinetic parameters $\left(\mathrm{C}_{\max }\right.$, $\mathrm{T}_{\max }, \mathrm{AUC}_{0-8 \mathrm{~h}}$ and MRT) following administration of the drug and its co-precipitate were compiled in Table 4. The pharmacokinetic parameters for the selected formula and pure drug were analyzed using one way analysis of variance using (SPSS computer program).

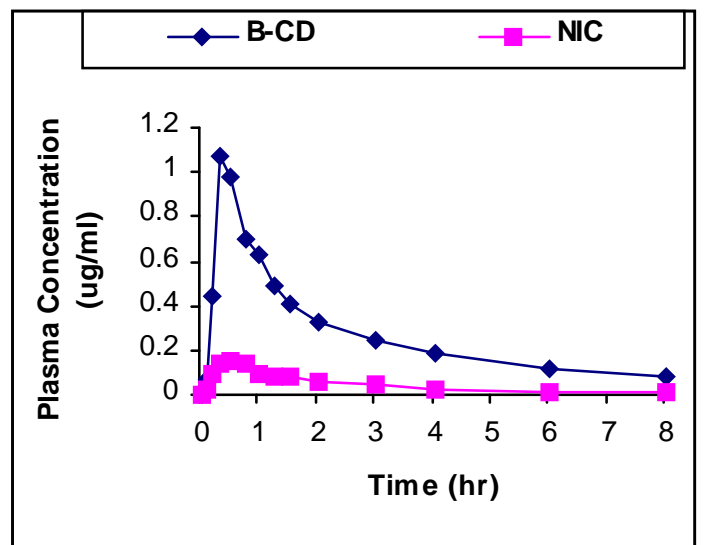

Fig. 12: Mean plasma levels of (NIC) following the oral administration of different nicardipine $\mathrm{HCl}$ preparations (equivalent to $4.2 \mathrm{mg} / \mathrm{kg}$ NIC) in rabbits.

Table 4: Mean values (mean \pm SD) of pharmacokinetic parameters after oral administration of nicardipine $\mathrm{HCl}$ in various formulations (equivalent to $4.2 \mathrm{mg} / \mathrm{kg}$ NIC) to rabbits.

\begin{tabular}{||c|c|c||}
\hline Parameter & "NIC" & $\begin{array}{c}\text { NIC- } \beta \text {-CD } \\
\text { "IC" (1:10) }\end{array}$ \\
\hline $\mathrm{C}_{\max }(\mathrm{ug} / \mathrm{ml})$ & $0.167 \pm 0.112$ & $1.079 * \pm 0.006$ \\
\hline $\mathrm{T}_{\max }(\mathrm{h})$ & $0.53 \pm 0.12$ & $0.39 \pm 0.0056$ \\
\hline $\begin{array}{c}\mathrm{AUC} \\
\text { (ug.8h }\end{array}$ & $0.352 \pm 0.446$ & $2.129 * \pm 0.238$ \\
\hline MRT $(\mathrm{h})$ & $2.26 \pm 0.12$ & $2.39 \pm 0.21$ \\
\hline $\begin{array}{c}\text { Relative bio- } \\
\text { availability (\%) }\end{array}$ & - & 605.3 \\
\hline \hline
\end{tabular}

*The mean difference is significant at the 0.05 level.
Compared to administration of plain (NIC), the administration of $\beta-C D$ inclusion complex increased $\mathrm{C}_{\max }$ and $\mathrm{AUC}_{0-8 \mathrm{~h}}$ values of (NIC). As an example, the ratio of mean $\mathrm{AUC}_{0}$ $8 \mathrm{~h}$ between NIC- $\beta$-CD and pure (NIC) was 6.048. $\mathrm{T}_{\max }$ and MRT values of (NIC) were not affected by CD co-administration. From these results, it could be concluded that the administration of $\beta-\mathrm{CD}$ co precipitate, very significantly improved the extent rather than the rate of drug absorption.

Savolainen et al., ${ }^{23}$ reported a significant increase in Cmax and AUC of phenytoin while $\mathrm{T}_{\max }$ and MRT values were not affected after the oral administration of phenytoinulfobutylether- $\beta-C D$ in comparison to the plain drug. They attributed these results to the increase in solubility and dissolution rate of the drug due to the $\mathrm{CD}$ complex formation. However, as noted by Uekama et al. ${ }^{39}$ it is also possible that cyclodextrins may affect drug absorption through modification of the mucosal membrane. Free cyclodextrin may remove membrane components, thereby modifying the transport properties of the membrane and facilitating absorption of the drug. ${ }^{40,41}$

\section{Conclusion}

Although, both $\beta-\mathrm{CD}$ and HP- $\beta-\mathrm{CD}$ proved to be active in performing solid-state interaction i.e.amorphization or reduction in nicardipine crystallinity, $\beta-\mathrm{CD}$ showed higher complexing and dissolution properties towards the drug than HP- $\beta$-CD. Moreover, in addition to the type of the (CD) employed, the selection of the most suitable preparation technique was a decisive factor to optimize the performance, and particularly the dissolution properties of the final solid product.

NIC- $\beta$-CD inclusion complex, is markedly superior in improving the extent of drug absorption, compared to the plain nicardipine $\mathrm{HCl}$.

\section{REFERENCES}

1- M. B. Maurin, S. M. Rowe, C. A. Koval and M. A. Hussain, J. Pharm. Sci., 83, 1418 (1994).

2- M. Ozyazici, F. Sevgi and G. Ertan, Drug Dev. \& Ind. Pharm., 23 (8), 761 (1997). 
3- C. Dollery, Therapeutic Drugs, $2^{\text {nd }}$ edition, Harcourt Brace and Company Limited, U.K, N65 (1999).

4- D. Duchene and D. Wouessidjewe, Drug Dev. \& Ind. Pharm., 16 (17), 2487 (1990).

5- T. Loftsson and R. O'Fee, Business Briefing: Pharmatech., 136-140 (2002).

6- P. Mura, G. P. Bettinetti, A. Manderioli, M. T. Faucci, G. Bramanti and M. Sorrenti, Int. J. Pharm., 166, 189 (1998).

7- A. M. Aly, M. K. Qato and M. O. Ahmed, Pharm. Technol., June, 55 (2003).

8- B. N. Nalluri, K. P. Chowdary, K. V. Murthy, A. R. Hayman and G. Becket, AAPS Pharm. Sci. Tech., 4 (1), E2 (2003).

9- S. A. El-Kheshen, S. M. Ahmed, O. A. Sammour andB. T. Al-Quadeib, Pharm. Ind., 64 (6), 612 (2002).

10- M. Francois, E. Snoeckx, F. Wouters, E. De Proost, U. Delaet, J. Peeters and M. E. Brewster, AAPS Pharm. Sci., 5 (1), 50 (2003).

11- S. Sridevi, A. S. Chauhan, K. B. Chalasani, A. K. Jain and P. V. Diwan, Pharmazie, 58 (11), 807 (2003).

12- A. Rolland and B. Shroot, J. Invest. Dermatol., 100, 219 (2000).

13- A. Latrofa, G. Trapani, M. Franco, M. Serra, M. Muggironi, F. P. Fanizzi, A. Cutrignelli and G. Liso, Eur. J. Pharm. Biopharm., 52 (1), 65 (2001).

14- T. Higuchi and K. A. Cannors, Adv. Anal. Chem. Instrum., 4, 117 (1965).

15- G. F. Palmieri, P. Welhrle and S. Martelli, Drug Dev. \& Ind. Pharm., 24 (7), 653 (1998).

16- M. O. Ahmed, I. El-Gibaly and S. M. Ahmed, Int. J. Pharm., 171, 111 (1998).

17- F. Veiga, J. J. C. Teixeira-Dias, F. Kedzierewicz, A. Sousa and P. Maincent, ibid, 129, 63 (1996).

18- F. Veiga, C. Fernandes and P. Maincent, Drug Dev. \& Ind. Pharm., 27 (6), 523 (2001).

19- S. A. Said, A. I. M. Ebid, O. Abd-El-Aziz and A. Abd-El-Aziz, Az. J. Pharm. Sci., 27, 133 (2001).

20- S. Kobayashi, K. Nakashima and M. Arahira, Carbohydr. Res., 192, 223 (1987).

21- A. M. A. Sabati, PH.D Thesis, Zagazig University (2002).
22- M. Gibaldi; Biopharmaceutics and Clinical Pharmacokinetics, $4^{\text {th }}$ edition, Philadelphia, (1991).

23- J. Savolainen, K. Jarvinen, L. Matilainen and T. Jarvinen, Int. J. Pharm., 165, 69 (1998).

24- R. A. Rajewski and V. J. Stella, J. Pharm. Sci., 85, 1142 (1996).

25- H. O. Ammar, M. Ghorab, S. A. ElNahhas, S. M. Omar and M. M. Ghorab, Pharmazie, 51 (1), 42 (1996).

26- J. Blanco, J. L. Vila-Jato, F. Otero and S. Anguiano, Drug Dev. \& Ind. Pharm., 17, 943 (1991).

27- H. Arima, K. Younomae, K. Miyake, T. Irie, F. Hirayama and K. Uekama, J. Pharm. Sci., 90 (6), 690 (2001).

28- C. M. Fernandes, T. M. Vieira and F. J. Veiga, Eur. J. Pharm. Sci., 15, Nr. 1, 79 (2002).

29- O. I. Corrigan and T. Stanely, J. Pharm. Pharmacol., 34, 621 (1982).

30- S. Tenjarla, P. Puranajoti, R. Kasina and T. Mandal, J. Pharm. Sci., 87 (4), 425 (1998).

31- K. Uekama, S. Narisawa, F. Hirayama and M. Otagiri, Int. J. Pharm., 16, 327 (1983).

32- R. B. Gandhi and A. H. Karara, Drug Dev. \& Ind. Pharm., 14, 657 (1988).

33- D. D. Chow and A. H. Karara, Int. J. Pharm., 28, 95 (1986).

34- A. P. Simonelli, M. M. Meshali, A. H. Abdel-Gawad, H. M. Abdel-Aleem and K. E. Gabr, Drug Dev. \& Ind. Pharm., 20, 2741 (1994).

35- C. A. Ventura, S. Tirendi, G. Puglisi, E. Bousquet and L. Panza, Int. J. Pharm., 149, 1 (1997).

36- P. Mura, M. T. Faucci, A. Manderioli and G. Bramanti, ibid, 193, 85 (1999).

37- M. Charoenchaitrakool, F. Dehghani and N. R. Foster, ibid, 239, 103 (2002).

38- E. Larrucea, A. Arellano, S. Santoye and P. Yagartua, Drug Dev. \& Ind. Pharm., 27, Nr. 3, 251 (2001).

39- K. Uekama, F. Hirayama and T. Irie, Drug Targeting Delivery, 3, 411 (1994).

40- T. Irie, Y. Tsunenari, K. Uekama and J. Pitha, Int. J. Pharm., 43, 41 (1988).

41- K. Nakanishi, T. Nadai, M. Masada and K. Miyajima, Chem. Pharm. Bull., 40, 1252 (1992). 